\title{
SAFE-Biopharma Standard
}

National Cancer Institute

\section{Source}

National Cancer Institute. SAFE-Biopharma Standard. NCI Thesaurus. Code C142675.

A standard established by the biopharmaceutical industry to digitally identify subscribers,

mitig ating legal, regulatory, and other business risks associated with electronic transactions. 